\title{
Enhancing local policymakers' capacity in environmental governance in the Philippines
}

\author{
Joy Molina Mirasol, Felix S. Mirasol, Jr., Estela C. Itaas and Benjamin Maputi
}

\section{Context}

The forest land in the province of Bukidnon, Philippines, is continuously declining in terms of its economic and environmental capacity. Forest destruction by timber poachers and conversion of forest land for agriculture are rising to an alarming level, leaving the remaining forest cover significantly below the desired 45 percent cover to sustain its services. Such decline and destruction are largely attributed to the inadequate and poorly implemented environmental laws and policies that sometimes lead to the rapid exploitation of timber from old growth forests, at prices far below real market. Thus, Acosta (2001, 2003) called on the government and challenged the academy and other agencies to be more aggressive about measuring the efficacy of government programmes and policies on a range of environmental concerns.

Collaborative efforts among the academy, NGOs and local government units (LGUs) have to be pursued to achieve good environmental management in local governance, economic growth and to prevent further damage to environment and natural resources. In 2006, Bukidnon State College, now Bukidnon State University (BSU), responded to the challenge by signing a memorandum of agreement with Tanggol Kalikasan (TK), an NGO, to assist local policymakers and upland volunteers in increasing their capacity to sustainably manage natural resources within their territories.

In line with this plan, BSU Institute of Environmental Governance (IEG) was established to carry out programmes aimed at providing the needed capacity for local executives and local policymakers to better perform their mandate as provided under the Local Government Code. The Code, among others, provides for the devolution of national government powers to LGUs. Among the devolved functions, previously under the Department of Environment and Natural Resources (DENR), are pollution control and solid waste management, management of communal forest resources, integrated social forestry, control over small-scale mining and related functions for the protection of the environment. Fisheries management and regulatory functions in municipal waters have likewise been devolved to local governments.

Local policymakers are specifically tasked with implementing policies relative 
to the above-cited functions. Indeed, the passage of the Local Government Code and other relevant environmental legislation increased the powers and responsibilities of local governments in the management of natural resources, and further broadening their role of environmental governance. However, the fact that powers and functions have been devolved does not mean actual transfer of capacity of accountabilities and responsibilities. There is still a need for implementers to be aware of the environmental issues and concerns, and identify their order of priority. It is on this premise that IEG was instituted.

The IEG offered a series of trainings with municipalities along the buffer zone of protected areas in Bukidnon Province, to equip local policymakers with basic environmental knowledge as they are the prime movers in environmental management.

To carry out the training, the partners pooled their resources. The university is responsible for the venue, facilities and other logistics; LGUs are responsible for providing meals. Tanggol Kalikasan provides an honorarium for resource persons while the DENR provides technical expertise and assists BSU in monitoring training results.

\section{Organizational/structure}

BSU hosts the Institute in partnership with TK and other local partners. IEG is jointly managed by BSU and TK under the Extension Director who serves as coordinator, assisted by the University Research and Development unit and a faculty member. The Institute is directly under the Office of the President and coordinates with partners from the LGUs and national government agencies such as the DENR and the National Commission on Indigenous Peoples (NCIP).

The project had a duration of two years, 2006 to 2008. The university-based researchers and TK constructed the Training Needs Assessment (TNA) instrument. This was further validated and translated by BSU into local dialect with assistance from the local community. The training was based on the results of the TNA. Training modules were collectively developed by the university, TK, DENR and the community. Resource persons with local expertise came from partner organizations.

Key stakeholders' involvement in the project and their roles:

- LGU: source of data on local environment-related concerns, financial support and participant transport.

- DENR: source of data on environment-related concerns, resource persons and technical expertise.

- Tanggol Kalikasan: human resources for environmental lawyers and financial support.

- Bukidnon State University: overall coordination of partners, facilitation of TNA, preparation of training design, management of training, facilitators, resource persons and monitoring and evaluation of the plan of action. 
The objectives were:

- to conduct training needs assessment on environmental governance in Bukidnon province to find out the needs of the local policymakers in relation to local environmental governance;

- to design trainings and develop modules for local policymakers;

- to analyse issues and concerns confronting local policymakers in environmental governance;

- to generate and formulate relevant policy recommendations;

- to facilitate enactment of policies in response to the recommendations.

Changes occurred based on the trainings results, particularly on the need for a refresher course for DENR site enforcers on basic environmental law enforcement and the implementation of the participants' action plan. Likewise, additional topics were included, particularly those with local applications, such as the Mt. Kitanglad Act of 2000, and climate change.

\section{Activities}

- Training needs assessment (TNA), conceptualization of the training design including selection of trainers, module formulation and implementation of training, with emphasis on coordination with partners, particularly from the LGUs, and monitoring and evaluation.

- Conducted the TNA. This aimed to assess the needs of every barangay, including those volunteers for the protected areas. The barangay is a smallest political unit or a village, led and governed by barangay officials - a barangay captain (Punong Barangay) and seven Barangay Kagawads (councillors). The local policymakers who serve as respondents in this project were barangay officials which include the barangay captain and the kagawad who chairs the environment committee.

- Identified trainers: trainers who are experts in the environmental governance and sustainable farming systems, including government agencies, the NCIP, academe, model farmers and environmental lawyers were invited to train the local policymakers.

- Implemented the training: two trainings were conducted in eight municipalities and one city.

- Monitoring and evaluation. Feedback was gathered during and after training sessions. Evaluation was done immediately after the training. After six months, the local policymakers, who were the primary participants, were monitored and evaluated. Evaluation was based on the action plans prepared during the training.

It was hoped that the project would increase the capacity of the local policymakers to implement their mandate with respect to environmental governance. Likewise, it is hoped that the project will contribute to the capacity to establish linkages with partners to assist them in the implementation of their action plan, 
and to influence other policymakers in the area of environmental consciousness. Knowledge gain can be translated in the formulation of the local environmental plan, leading towards improved local environmental governance for the benefit of community.

To attain effective and functional undertakings, project implementers first identified key environmental issues, concerns and priorities of local policymakers in relation to natural resources management. This was carried out through a TNA in the different provincial municipalities surrounding the protected areas of Mts. Kitanglad and Kalatungan. TNA results served as the basis for the proposed training design and modules. The TNA and other data collections were undertaken during the Protected Area Management Board (PAMB) meetings since most local policymakers are board members.

The training programme used the Integrated Ecosystem Approach (IEA) which takes into account common resource bases such as rivers, bays, gulfs, watersheds, declared protected areas. Priority was given to participants from the buffer zone of the protected areas as most of these resources require a more intense resource management due to pressures from issues and problems confronting the park. The Institute also endeavoured to design the training programme towards specific and measurable impacts on the common resource.

The training was conducted in a participative and collaborative manner. Focus group discussions and interviews with the local policymakers were undertaken. The same methods were also used with the DENR provincial, city and municipal officials to validate the issues raised by local policymakers in the needs assessment, during, and after the training.

The Integrated Ecosystem Approach outlined twelve complementary and interlinked principles (UNEP, 2003). These principles stress that working together with partners plays a vital role in project success. The second and twelfth principles (UNEP, 2004), in particular, provide that management should be decentralized to the lowest appropriate level and that this approach should involve all relevant sectors of society, and scientific discipline. Further, it was recognized by project partners that no single institution has all expertise and resources to respond to the challenge of good environmental governance and that resource pooling is the best option. Institutional commitment through a memorandum of agreement is considered an important instrument in this approach.

As post-training evaluations among partners were conducted which recognized our best practices and documented the lessons learned, the approach was modified to fit the needs of local policymakers.

\section{Outcomes}

The initial outcomes of the project include: (1) identification of environmental issues and concerns at the local level in relation to the provision of the Local Government Code and other relevant legislation; (2) formulation of the training design based on their needs; (3) development of training modules; (4) preparation of action plans; and (5) action plan implementation as presented below. 


\section{Identification of issues and concerns}

Mt. Kitanglad Range Natural Park was declared a protected area by Congress pursuant to the National Integrated Protected Area System Law (Mirasol and Itaas, 2008, 2010; Mirasol and Saway, 2005). Several environmental and operational issues were identified as confronting the protected area management of these areas. The issues were identified by local policymakers involved in the decision-making process and the management of the park (barangay captains, chairs of the committee on environment and the Kitanglad Guard Volunteers (KGV). In this chapter, they are called local policymakers (LPMs). Some identified the following issues:

- lack of funding to sustain efforts toward the conservation of biodiversity, environmental education for the preservation of endangered species in the Protected Area, and insufficient financial assistance to sustain the operation of the Mt. Kitanglad Guard Volunteers;

- peace and order condition of the area hindering volunteer patrol work;

- climate change and carbon sequestration issues created increased demands and pressure on volunteers for more forest preservation initiatives and endeavours;

- sales of land in the buffer zone of Mt. Kitanglad and the adjoining Mt. Kalatungan still exist despite their proclamation as protected areas, contributing to forest denudation and unregulated collection of park species;

- poor implementation of watershed management plan. Most of the barangays are still in the process of formulating their respective watershed development plans;

- limited understanding of watershed management issues and the unpredictability of many natural and human-induced events, including land use change and development trends that contribute to the uncertainty of management decisions and research development outcomes;

- forest encroachment and expansion of intensive agriculture and unsustainable farming practices are only few examples of the many complex issues confronting the uplands. (Garrity et al., 2002).

There is a need for more cooperation among various sectors of society in ecological solid waste management as this project has a limited programme for information dissemination and environmental education.

A training design was formulated based on the result of the training needs assessment. The design effectively considered the selection of participants and gave emphasis to local officials and volunteers actually engaged in environmental governance. Instruction was conducted in the local dialect (bisaya) to ensure deeper understanding and open communication among the participants.

The methodology was participative and collaborative in nature, ensuring active participation throughout the whole training. The TNA and other data collection was undertaken during Protected Area Management Board (PAMB) meetings since most of these local policymakers are members of the PAMB and Association of Barangay Council (ABC), as in the case of the Poblacon Barangay Chairs. Focus 
group discussion interviews with local policymakers and others were undertaken.

Topics discussed included: (1) Local Environmental Situations; (2) Basic Ecological Concepts; (3) Community-Based Forest Management Framework and RA 7586, the National Integrated Protected Area System (NIPAS) Act; (4) RA 9003, the Ecological Solid Waste Management Act; (5) Watershed Management; (6) Agroforestry; (7) RA 8978, the Mt. Kitanglad Act 2000; (8) Concepts and Principles of Sustainable Development; (9) Sustainable Agriculture and Organic Farming; (10) Indigenous Peoples Rights Act (IPRA); (11) Relevant Environmental Policies; and (12) Basic Enforcement Skills.

These topics were discussed using varied techniques including workshops, demonstrations and lectures to ensure that participants were fully engaged in the various activities. Enough time was given for an open forum for the local policymakers to clarify grey areas regarding the topics and to share their ideas. After a series of interactions, evidence shows that local policymakers have exerted efforts, given priority to environmental governance and taken action by projects including tree planting, nursery, rainforest reforestation and watershed protection in their barangays.

The development of training modules followed three stages. First - the predevelopmental stage was concerned with planning, identifying the scope, purpose and objectives, determining time allotment and developing the Task Analysis Table. The identification of topics was grouped - learning about the environment, learning in the environment and learning for the environment. Secondly, the developmental stage focused on writing on the topics identified in the TNA. Lastly, the post-developmental stage focused on the validation and revision of the modules. In this stage, the evaluation of the modules was done by a panel of experts and the test group composed of LPM from Malaybalay City. The modules were then revised based on the results of the validation. These were written in English, and were eventually translated into the commonly used local dialect.

\section{Action plans}

After a series of presentations, the capacity development training culminated in a consolidated action planning workshop (Mirasol \& Itaas, 2010), resulting in the following programmes and activities: Community-Based Forest Management (CBFM); Protected Area; Watershed; Ecological Solid Waste Management; Forest Protection Works; and Capacity Development.

In the area of community-based forest management (CBFM), a re-orientation was needed for the members of the association, an activity that would assist them in the formulation and packaging of livelihood projects. Bamboo and abaca planting in the protected area were included in the activities along the buffer zone of Mt. Kitanglad Range Natural Park and even in the watershed areas. Information campaigns and protection of endangered species were also suggested as major activities. Plans on an information drive and establishment of the Material Recovery Facility and station buying centres were included in the Ecological Solid Waste Management programme. For protection works, the LPMs have included an information campaign, the establishment of fire lines and firebreaks and patrolling of the Kitanglad Guard Volunteers. 
Last but not the least is capacity development. They have included eco training as part of the activity so that members in the community not able to attend the training may also learn about basic environmental principles and laws, and other topics discussed during training.

After the training, focus group interviews and discussions were conducted to monitor the follow through on the plans of action. Outcomes were as follows:

- Thirty barangays created barangay solid waste management committees and passed ordinance on Environmental Solid Waste Management;

- Formulation and implementation of five barangay ordinances and four resolutions on forest protection and management;

- Barangay ordinance - 'No contour farming, no assistance' - was passed and implemented in four barangays.

- Conducted eco training for other LPM not able to participate in training;

- Twenty-eight local policymakers within the Mt. Kitanglad Range Natural Park organized a meeting with the Protected Area Superintendent to discuss their powers and functions as Protected Area Management Board members;

- They strengthened the operation of their forest protection volunteers by way of the deputation order issued by DENR;

- Solicited twenty-eight cellular phones from SMART Communications for barangay volunteers;

- After reports from the barangay volunteers $1,460 \mathrm{bd}$. ft. of lumber was confiscated for violation of forestry rules and regulation;

- Council of Elders (Indigenous Peoples);

- Enforcement of tribal justice system with emphasis on the environmental principles;

- Strengthened operations of tribal guards within its territory.

\section{City government}

- The City Government of Malaybalay assigned summer job students to work in the barangay nursery. Based on a report submitted to the City Planning Office, some 18,000 seedlings were raised;

- Conducted participatory multi-sectoral watershed characterization study within the four barangays.

It was noted that LPM capacity building resulted not only in aggressive enforcement of environmental laws but also in implementation of various programmes to carry out their mandate as members of the LGU.

There is increased awareness and skills of LPMs which can be converted into action through ordinances and programmes by incorporating environmental activities in their annual investment plans. There will be a proactive policy formulation to address the issues and concerns identified during the trainings.

LPMs became very interested in sustainable upland farming systems to increase their long-term production as a sustenance source. These include agroforestry development, contour farming, livestock production and traditional pest 
management. The purchase of quality planting materials has now been included in the barangay plan for the establishment of demonstration farms and for distribution. Likewise, consciousness of biodiversity values has been seen through the ban of air guns to catch and/or kill wildlife species. The LPMs and local community were accordingly now practicing waste segregation in their respective households.

Soil and water conservation measures increased production, improving economic conditions of the upland communities. This is coupled with crop diversification and sustainable upland agriculture principles. Politically, greater participation in planning was seen, and inclusion of environmental activities in annual investment plans. Other impacts include biodiversity, culture and the overall governance of the ecosystem.

\section{Challenges}

1 The project entails a significant amount of time in terms of coordination with LGUs. For example, local chief executives often personally interact with LGUs to ensure participation and financial assistance. This was addressed by establishing contact persons at the office of the chief executive to ensure that an appointment is set before the actual visit. Likewise, proactive planning has to be made for proper scheduling of transportation.

2 Ensuring focus during training on the part of the participants can be challenging as many of them have other businesses and/or other duties that compete for their time. Though it entails higher resources, the training was conducted in areas far from their respective stations (i.e., BSU campus).

3 After the project, duration funds coming from TK became very limited. To address this concern, the project coordinator made representation with the university president and the local chief executive regarding training co-financing. Now the LGU covers participants' transportation and food requirements, while the university handles supplies and remuneration of resource persons/ facilitators.

4 Availability of partners during joint activities as most hold key positions with their respective institutions: The schedule is agreed to in advance; however, if availability is still an issue it is the partners' responsibility to assign another representative, or send materials for training presentations.

5 Upgrading of information to make training module relevant and responsive to the current issues: To generate relevant information needed to update the modules, the university included the concerns for the environment in one of its research programmes. Likewise, the monitoring report submitted by the participants was collected and collated in the project coordinator's office.

6 Duplication of activities by the Department of Interior and Local Government: The project endeavoured to include them as part of participants' training.

7 Change of administration of the LPMs every four years: The training not only includes the barangay chairs but also potential successor of the barangay chair. This is, however, based on the personal assessment of the chief executive. 


\section{Success factors}

- The training is needs driven and considers the mandate of the Local Government Code and the Ecological Solid Waste Management Act for LGUs to act as the lead implementing units. The issue of climate change has created pressure on the LPMs and local farmers; this was also discussed during the training.

- The unconditional support from the university president, and the mindset of the Bukidnon political leaders who are advocating a total log ban and expressing their opposition to the passage of logs from neighbouring provinces and cities, and the financial support from the LGU local chief executives.

- Presence of partners, e.g., DENR, who can respond quickly to local environmental issues confronting LPMs, and the environmental lawyers from TK who can respond with legal impediments as perceived by law enforcement participants.

- Partner institution included project activities in their annual key result area targets.

- Effective networking and linkages with other agencies.

- Protected areas volunteers are already engaged in environmental law enforcement, hence its built-in interest in basic environmental law.

- Action plans developed during the training have been incorporated into the LGU investment plan.

- Memorandum of Agreement clearly defined roles of stakeholders and partners.

\section{Lessons learned}

Throughout the course of this project the partners learned that environmental management can be implemented successfully by bringing the decision-making process from the central government to the key local officials.

Decentralization should also recognize the significant participation of the stakeholders, such as NGO's, local communities and tribal communities.

The academy has a significant role in advancing environmental management in collaboration with partners and stakeholders.

Proper collaboration with LGUs resulted in resource generation for project undertakings.

\section{Recommendations}

- There is a need to conduct environmental management and governance training with the newly elected local policymakers. This effort shall be spearheaded in partnership with the LGUs and the academy.

- Refresher training for law enforcers in the barangay/tribal territory level is needed. 
- Ensure sustained environmental training by including proposed activities in the annual investment plan of the concerned LGUs.

- A reward system to recognize the LGUs with best records in environmental governance is necessary.

- Build up local pool of environmental advocates and trainers to reach out to more areas and LGUs and encourage multi-sectoral participation, particularly from indigenous peoples and women.

- The academy should include environmental programme and advocacy as one of its top priorities, through its research and extension units. 